\title{
Optimization of Product Distribution in the Heavy Oil Vacuum Residue High Value-added Process by Using Additives
}

\author{
Shiguang Fan ${ }^{1}$, Guanjun $\mathrm{Xu}^{1}$, He Liu ${ }^{1 *}$, Jian Wang ${ }^{1}$, Zongxian Wang ${ }^{1 *}$, Shengnan $\mathrm{Sun}^{2}$, and Bernard Wiafe Biney ${ }^{1}$ \\ ${ }^{1}$ State Key Laboratory of Heavy Oil Processing, College of Chemical Engineering, China University of Petroleum (East China), Qingdao, \\ Shandong, China. \\ ${ }^{2}$ Chemical Engineering Department, Qingdao Product Quality Supervision and Testing Research Center, Qingdao, Shandong, China.
}

\begin{abstract}
The increase in demand for fuel oil has brought higher challenges to the high value-added process of heavy oil vacuum residue, especially for delayed coking units. For optimization of product distribution, the effects of reaction temperature and chemical additives were discussed. The results show that high temperature and $1 \mathrm{wt} \%$ of the heteropoly acid (HPA) could increase the light oil yield in the experimental delayed coking simulation device.
\end{abstract}

\section{Introduction}

With the increase in the global heavy oil resources exploitation and the market growth in demand for light fuel oil, the high value-added technologies of heavy oil residues are attracting more attention in oil refineries [1]. Moreover, the progressively stringent requirements for clean oil by the environmental protection have spawned more precise methods to control the operating conditions to optimize the product distribution [2]. However, the heavy oil vacuum residues are exceedingly difficult to process because of high density, high viscosity, high content of heteroatoms, high carbon residue, and low $\mathrm{API}^{\circ}[3]$. Therefore, a more practical and flexible method to optimize heavy oil vacuum residue process could be one of the most challenging tasks.

Delayed coking is a classic process to produce high value-added products, which could convert the heavy oil vacuum residue to gasoline, diesel and coke etc. With the advantages of strong material adaptability, mature technology, low investment and high conversion rate, the delayed coking unit is indispensable for modern refineries[4]. With the increase in demand for light oil, to optimize the product distribution of delayed coking and to reduce the heteroatoms of products are the inevitable trend of delayed coking process development.

In the delayed coking process, the feedstock is heated to about $500{ }^{\circ} \mathrm{C}$ in less than half of one minute, and piped to the coke drum for thermal cracking reaction. It is a non-catalytic reaction unit of which the product yield and quality all depend on operating conditions, which presents limitations in flexible control of product distribution. So, chemical additives have drawn great attention to further optimize product distribution to produce more high value-added light oil [5-7]. In this work, the HPA, the selected additives, was investigated to discuss its influence on the product distribution of the delayed coking experimental device.

\section{Experimental section}

\subsection{Materials.}

The material used in this work was a typical heavy oil vacuum residue with the initial boiling point higher than $420{ }^{\circ} \mathrm{C}$. The properties of the material are shown in Table 1. The vacuum residue preparation was in accordance with the ASTM D2892-03a using a heavy oil distillation apparatus.

Table 1. Properties of the heavy oil vacuum residue

\begin{tabular}{|c|c|}
\hline Analysis & Value \\
\hline Initial boiling point, ${ }^{\circ} \mathrm{C}$ & $>420$ \\
\hline $\mathrm{API}^{\circ}$ & 6.9 \\
\hline Density $\left(20^{\circ} \mathrm{C}\right), \mathrm{g} / \mathrm{cm}^{3}$ & 1.0167 \\
\hline${\text { Viscosity }\left(100^{\circ} \mathrm{C}\right), \mathrm{mm}^{2} / \mathrm{s}}$ & 2056 \\
\hline Solidification point, ${ }^{\circ} \mathrm{C}$ & 48 \\
\hline Carbon residue, $\mathrm{wt} \%$ & 19.48 \\
\hline $\mathrm{S}$ content, $\mathrm{wt} \%$ & 3.48 \\
\hline $\mathrm{H} / \mathrm{C}$ atom ratio & 1.46 \\
\hline Ni+V, $\mu \mathrm{g} / \mathrm{g}$ & 405 \\
\hline
\end{tabular}

2.2 Apparatus and methods for reactions.

\footnotetext{
* Corresponding author: Liu: aoyun3002008@126.com; Wang: heavyoil@upc.edu.cn
} 
The delayed coking simulation experiments were carried out in a customized reactor, which contained a vacuum residue reaction tank, a light oil condense tube and a liquid product collection tank. The reactor containing 50 $\mathrm{g}$ of the vacuum residue was sealed and purged with nitrogen for 3 minutes. The reaction tank was preheated to $300{ }^{\circ} \mathrm{C}$ before placed into the coking reaction heater. The reaction time and pressure for all experiments mentioned in this work are $2 \mathrm{~h}$ and $0.1 \mathrm{MPa}$. The method of preparing colloidal liquid aphron (CLA) referred to Sebba's contribution [8]. After the coking reaction, the coke in the reaction tank and the liquid product in the collection tank were weighed. The yields of gasoline, diesel, light coker gas oil and heavy coker gas oil were measured by gas chromatography following the standard test method ASTM D2887.

\section{Results and discussion}

\subsection{Influence of temperature on product distribution under non-additive condition}

The delayed coking simulation experiments were conducted at $440{ }^{\circ} \mathrm{C}, 460{ }^{\circ} \mathrm{C}, 480{ }^{\circ} \mathrm{C}, 500{ }^{\circ} \mathrm{C}, 520{ }^{\circ} \mathrm{C}$, respectively, to investigate the influence of temperature on the product distribution. The relation between coking temperature and product yield is shown in Figure 1. When the reaction temperature increases, the thermal cracking reaction is enhanced. As shown in Figure 1, the liquid yield increases with temperature gradually, while the coke yield decreases, because the high temperature not only accelerate the cracking of more components in vacuum residue, but also promote the mass transfer from the reaction tank to the collection tank.

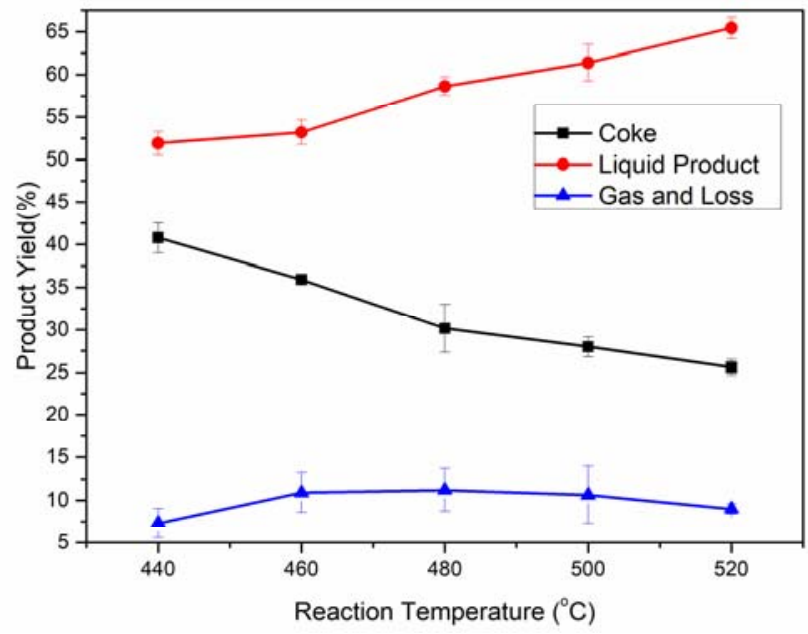

Figure 1. Influence of reaction temperatures on the coking product distribution

The liquid product distribution was also measured and presented in Figure 2. At low temperatures, there are almost no heavy coker gas oil fraction in the liquid collection. This is because the heavy coker gas oil (initial boiling point, IBP $>450{ }^{\circ} \mathrm{C}$ ) could not evaporate and flow into the condense tube. At higher temperatures, the heavy coker gas oil and light coker gas oil fractions are relatively increased, while the diesel fraction decreased.
This could be caused by the increased thermal cracking reaction rate at higher temperatures.

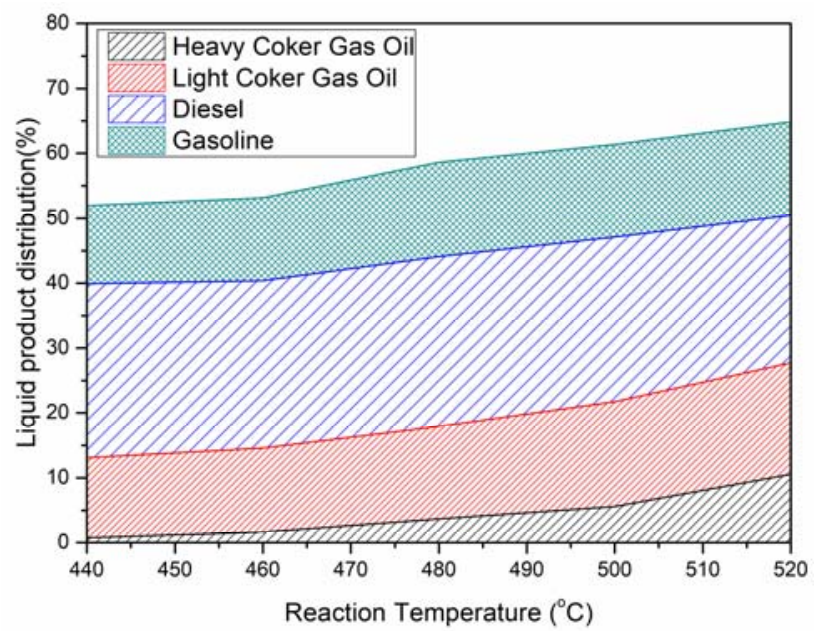

Figure 2. Influence of reaction temperatures on the liquid product distribution

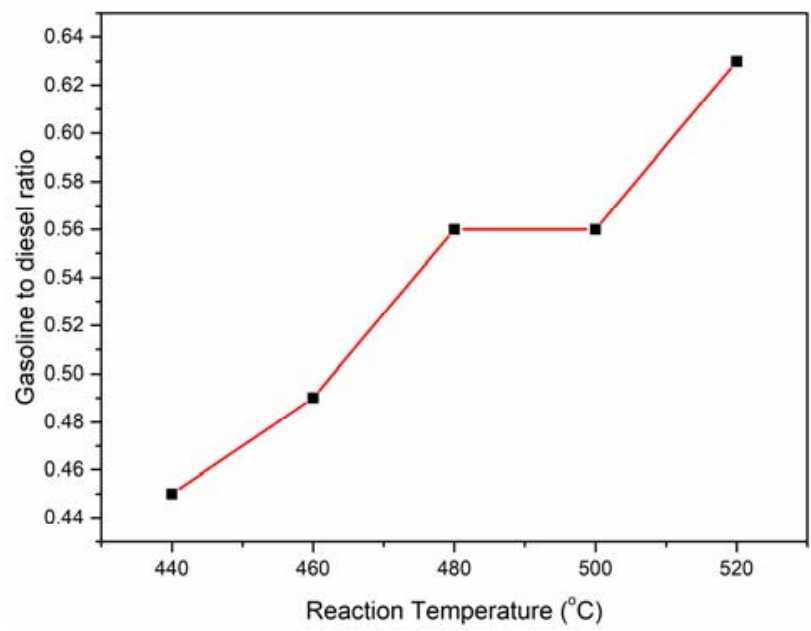

Figure 3. The gasoline to diesel ratio versus temperature

The gasoline to diesel ratio at different temperatures is also calculated, as shown in Figure 3. Compared with the low gasoline to diesel ratio at $440{ }^{\circ} \mathrm{C}$, this value could reach up to 0.63 at $520{ }^{\circ} \mathrm{C}$. Although the product distribution of the coking simulation experiments could be changed very regularly, this method is only suitable for experimental phase, because the coking furnace and the coking drum in industrial units are easily affected at higher operating temperature.

\subsection{Influence of HPA additives on product distribution}

The heteropoly acid (HPA) was selected as the additives to investigate its influence on the vacuum residue coking experiment. But the HPA is a water-soluble polyacid composed of metal atoms, heteroatoms and oxygen. For better dispersibility of HPA in the viscous vacuum residue, the ethanol and colloidal liquid aphron (CLA) were employed to help disperse the HPA particles. As shown in Figure 4(b), if ground and added directly, the HPA particles become large precipitates. When dissolved in ethanol, the HPA particles become smaller 
significantly (Figure 4c). The CLA presents outstanding performance in dispersing water soluble chemicals. After heated at $180{ }^{\circ} \mathrm{C}$ for $1 \mathrm{~h}$ to evaporate the original components in the CLA, the vacuum residue with additives presented no obvious particles under the microscope.
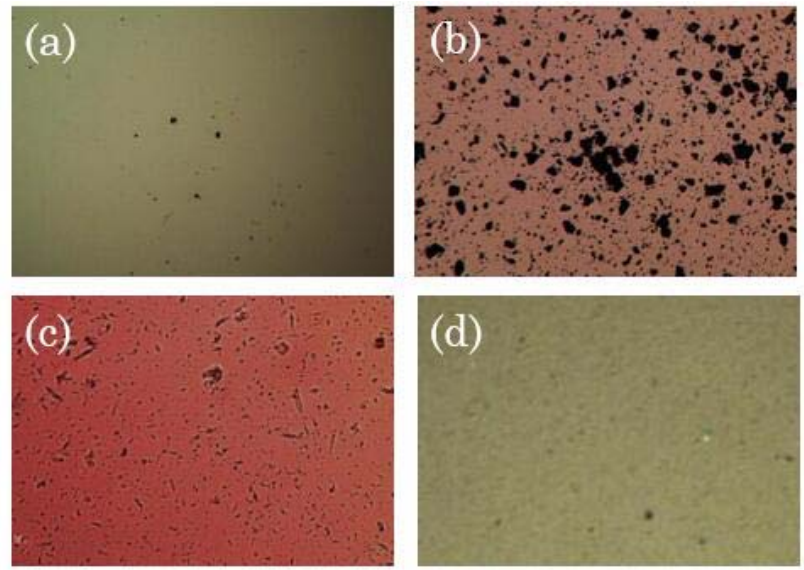

Figure 4. Photomicrographs of additives particles added by different ways in the heavy oil vacuum residue;

(a) the original solid particles in the feedstock, (b) ground and added directly, (c) dissolved in ethanol, (d) dissolved in the CLA. Magnification: X100.

The liquid product distribution optimized by the HPA at different temperatures is shown in Figure 5. The amount of HPA added in the vacuum residue was $1 \mathrm{wt} \%$. At low temperatures, there is no conspicuous difference in liquid yield. As the reaction temperature increases, the liquid yield starts to be affected by the additives. Compared with the liquid yield under no additives condition, most of the liquid yields at high temperatures are relatively lower, regardless of the way by which the HPA was added to the vacuum residue. The HPA has strong acidity and oxidizing, which could promote the polymerization reaction and coking reactions of vacuum residue components. And the HPA would be the center of coking reactions. Consequentially, the HPA reduces the liquid product yield.

Although the results show significant increase in coke yield and decrease in liquid yield, the HPA shows advantages in optimizing the subcomponents distribution of liquid products. The distillation range distribution of liquid products was analysed by GC according to the standard test method ASTM D2887, as shown in Figure 6 and Figure7. The diesel yields at each temperature are all increased irrefutably, compared with the diesel yield under no additives condition. At temperatures below $480{ }^{\circ} \mathrm{C}$, there is also significant increase in gasoline yield. But the gasoline yield would decrease at $520{ }^{\circ} \mathrm{C}$. This indicates that the added HPA in the vacuum residue could still play the catalytic role to promote cracking reactions to produce more light oil at high temperatures. And the yields of other subcomponents (light coker gas oil, heavy coker gas oil) in the liquid product also changed under the HPA catalytic conditions.

The HPA added in the vacuum residue would decompose and form metal oxides at about $450{ }^{\circ} \mathrm{C}[9]$. However, it would become metal sulphide quickly in the vacuum residue which has high content of $\mathrm{S}$ (Table 1). And the metal sulphide may be the main substance that plays a role in promoting the cracking reaction. There are still inherent metal heteroatoms in the vacuum residue (Table 1), which could promote the heavy oil cracking reaction under specific conditions. However, these metals mainly exist in the form of complex metal organics and are associated to polycyclic aromatic compounds $[10,11]$. It is difficult for them to convert to catalytically active metal species [12]. The added additives would inevitably increase the operation costs, though the products distribution could be promoted. How to release and convert the metal species in heavy oil to promote the heavy oil thermal reactions would be meaningful for heavy oil high value-added process.

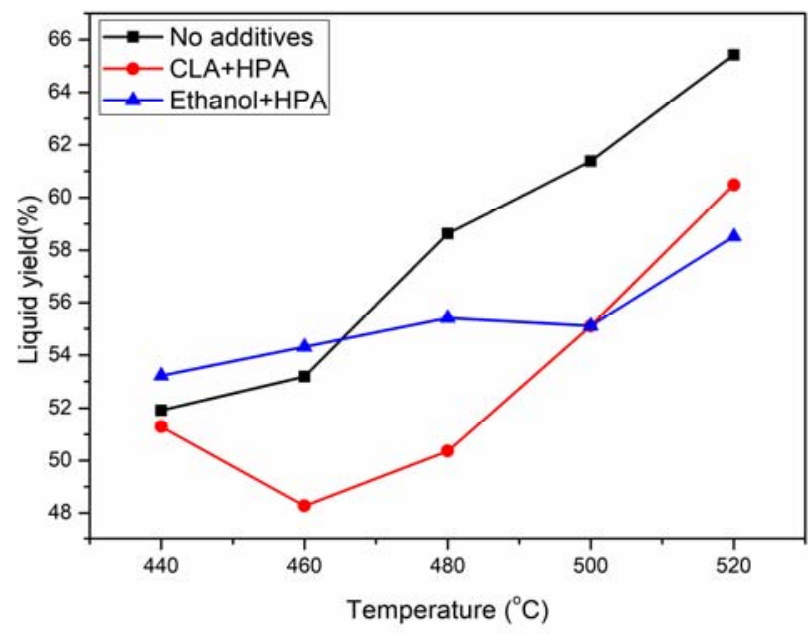

Figure 5. Effect of the HPA on the liquid yield at different reaction temperatures.

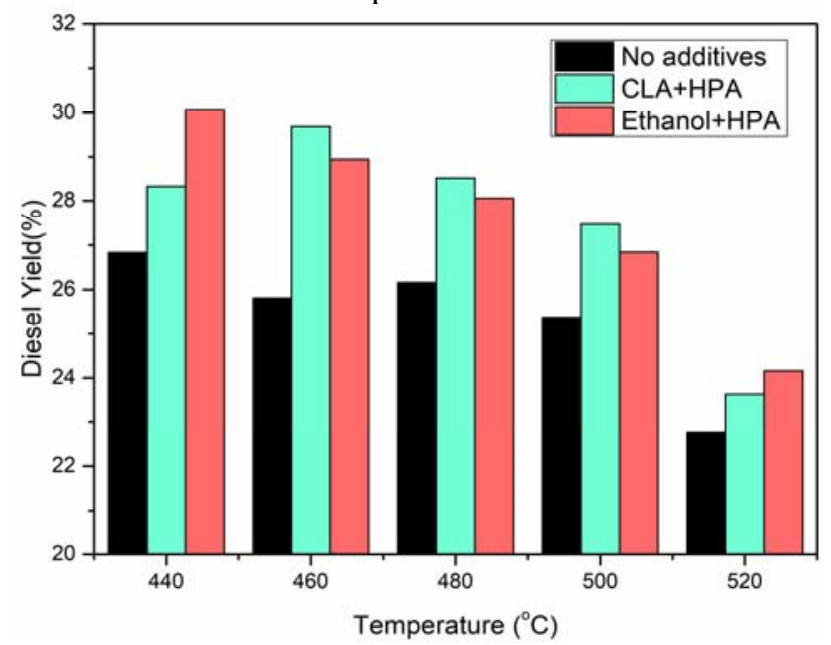

Figure 6. Effect of the HPA on the diesel yield at different reaction temperatures. 


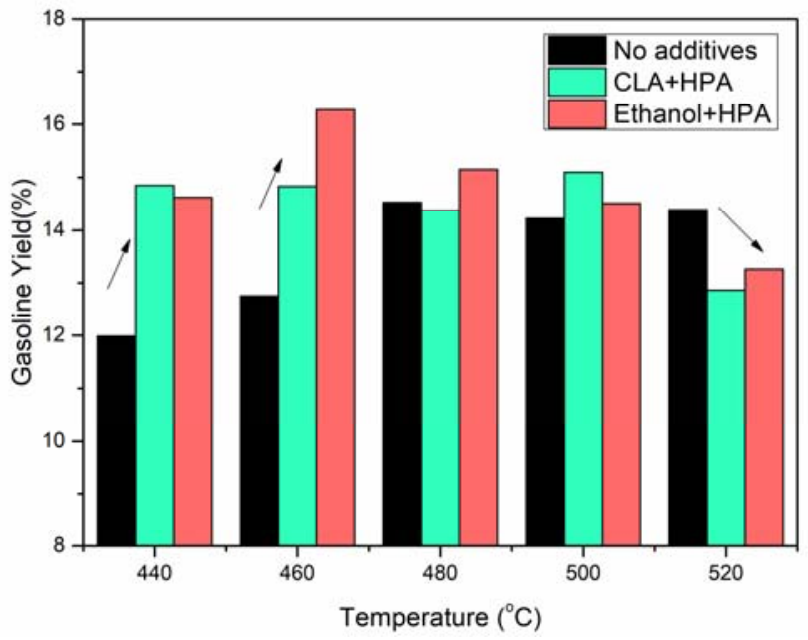

Figure 7. Effect of the HPA on the gasoline yield at different reaction temperatures.

\section{Conclusion}

By changing the reaction temperature, the product distribution of the coking simulation experiment could be optimized very regularly. But the limitation of changing the temperature is that the coking furnace and the coking drum in industrial units are affected easily at higher operating temperatures. So, the method of adding chemical additives to the vacuum residue could be an alternative method to optimize the product distribution for high yield of light oil.

\section{Acknowledgment}

This work was supported by the National Natural Science Foundation of China (Grant 21908248), the Fundamental Research Funds for the Central Universities (Grant 19CX02013A), the Provincial Natural Science Foundation of Shandong (Grant ZR2017BB021), the Provincial Postdoctoral Research Founding of Shandong (201702028), the State Key Laboratory of Heavy Oil Processing (SLKZZ-2017003).

\section{References}

1. P. Xue, S. Fan, X. Wang, K. Chen, H. Liu, W. Xia, A. Guo, Z. Wang, Energy fuels, 31, 1259 (2017).

2. K. Chen, H. Zhang, U.-K. Ibrahim, W. Xue, H. Liu, A. Guo, Fuel, 246, 60 (2019).

3. Z. Wang, S. Ji, H. Liu, K. Chen, A. Guo, Energy Technol., (2015).

4. Q. Chen, L. Gu, A. Guo, Z. Wang, Petrol. SCI. Technol., 1 (2019).

5. J.R. Roth, US Patent, 5645712, (1997).

6. C.L. Liang, B.X. Shen, J.C. Liu, S.K. Wu, Petrol. SCI. Technol., 27, 2158 (2009).

7. R.G. Etter, US Patent, US 8888991 B2, (2014).

8. V. Bergeron, F. Sebba, Langmuir, 3, 857 (1987).
9. E. Wang, J. Niu, L. Xu, D. Zhou, J. Inorg. Chem., 352 (1994).

10. S. Fan, H. Liu, J. Wang, H. Chen, R. Bai, A. Guo, K. Chen, J. Huang, Z. Wang, Energy Fuels, 34, 2683 (2020).

11. H. Liu, J. Mu, Z. Wang, S. Ji, Q. Shi, A. Guo, K. Chen, J. Lu, Energy Fuels, 4803 (2015).

12. H. Liu, S. Fan, Z. Wang, K. Chen, A. Guo, Chemistryselect, 2, 1613 (2017). 